\title{
Inequitable job accessibility across educational and hukou groups in Beijing: An analysis of transit-based accessibility to sectoral jobs
}

\author{
Tieshan Sun \\ Peking University \\ tieshansun@pku.edu.cn
}

\author{
Yingling Fan \\ University of Minnesota \\ yingling@umn.edu
}

Abstract: This paper documents inequitable transit-based accessibility to sectoral jobs among population groups with different educational attainment and hukou status in Beijing, China. A cumulative transitbased job accessibility measure is applied and multiple data sources are used, including the transit travel-time data from a Chinese web mapping service and the population and employment distribution data from the 2010 Population Census and the 2013 Economic Census of Beijing. We find clear differences in transit-based job accessibility among employment sectors and among population groups in Beijing. On average, jobs in the finance sector are the most accessible by transit, and jobs in the manufacturing sector are the least accessible by transit. Despite having the highest transit dependency, the low-educated migrant population has the lowest transit-based job accessibility regardless of employment sectors. The disparities are especially large when tying specific populations with specific sectors. Within 60 minutes, the low-educated migrant population using transit, on average, can only access $4.6 \%$ of total manufacturing jobs in Beijing. In contrast, the same measure for the highly educated local population accessing jobs in the finance sector is as high as $48.3 \%$. The findings suggest that general transit improvements and jobs and population redistribution efforts, without specific sectoral and population considerations, are unlikely to create equal access to job opportunities. In Beijing, greater attention must be paid to connect the low-educated migrant population to low-skilled and decentralized jobs in the manufacturing, construction, and transportation and storage sectors.

Keywords: equity, transit, job accessibility, sectoral jobs, population groups, migrant population

\section{Article history:}

Received: December 26, 2017

Received in revised form:

April 14, 2018

Accepted: May 26, 2018

Available online: October 19,

2018

Copyright 2018 Tieshan Sun \& Yingling Fan

http://dx.doi.org/10.5198/jtlu.2018.1367

ISSN: 1938-7849 | Licensed under the Creative Commons Attribution - Noncommercial License 4.0

The Journal of Transport and Land Use is the official journal of the World Society for Transport and Land Use (WSTLUR) and is published and sponsored by the University of Minnesota Center for Transportation Studies. 


\section{Introduction}

Equity has been a major concern in public transport, and inadequate transit supply could result in the social exclusion of vulnerable population groups who are disproportionately transit dependent, preventing them from having equal access to economic and social opportunities (Leck, Bekhor, \& Gat, 2008; Delbosc \& Currie, 2011; Xia et al., 2016). A lack of transit-based accessibility to employment opportunities can lead to low job participation and long-term poverty of people who are transit dependent (Sanchez, 1999; Fan, 2012; Fan, Guthrie, \& Levinson, 2012; Welch, 2013). In developed countries, especially in the U.S., transport equity and job accessibility for various population groups have been widely examined, such as for low-income (Niedzielski \& Boschmann, 2014; Hu, 2017), disabled (Lubin \& Deka, 2012), female (Matas, Raymond, \& Roig, 2010) and seniors (Engels \& Liu, 2011). In developing countries such as China, where the majority of the urban population relies upon public transportation for job access, it is critically important to examine transit inequity and job accessibility gaps among different population groups (Qi, Fan, Sun, \& Hu, 2018). However, due to data availability issues, very few studies from China have compared transit-based job accessibility across population groups of different socio-economic status (Jiang \& Levinson, 2017; Qi et al., 2018). In addition, existing job accessibility studies in China mostly ignored how transit-based access to jobs may vary across different industries. By using newly available data sources, this study provides new empirical evidence on population and sectoral differences in transit-based job accessibility in one of the most populous metro areas in China and sheds light on the issue of inequitable job accessibility in urban China.

\section{Study area and data sources}

The study area is the Beijing metropolitan area. Beijing is the capital city and the second-largest city in China by size of the population. The Beijing metropolitan area is representative of large Chinese metro areas in a number of ways, including the rapid urban expansion and the continuous suburbanization of the population experienced in recent decades, as well as the expansive public transportation systems and the increasing jobs-housing imbalance (Fan, Allen, \& Sun, 2014; Sun, Han, Wang, \& Li, 2012).

We define the Beijing metropolitan area to include the urban area and its adjacent outer suburbs of Beijing, which consists of 12 districts with a total area of 9,114.59 square kilometers. The 2015 population in the area was 20.11 million (Beijing Municipal Bureau of Statistics, 2016). As shown in Figure 1 , the 12 districts contain a total of 246 jiedaos (subdistricts). Jiedao has been the basic administrative spatial unit in Chinese cities for decades and is the lowest geographic level reported in publicly accessible government statistical reports (Gu, Wang, \& Liu, 2005).

The public transit systems in Beijing are expansive and the municipal government of Beijing continues to expand its transit systems following its "transit priority" policy. Figure 1 shows the bus and rail systems in the area. Fifty percent of all trips in the central urban area of Beijing in 2015 were made on public transit (Beijing Transport Institute, 2016), and the total annual public transit ridership in Beijing in 2015 was 7,383.84 million (Beijing Municipal Bureau of Statistics, 2016). 


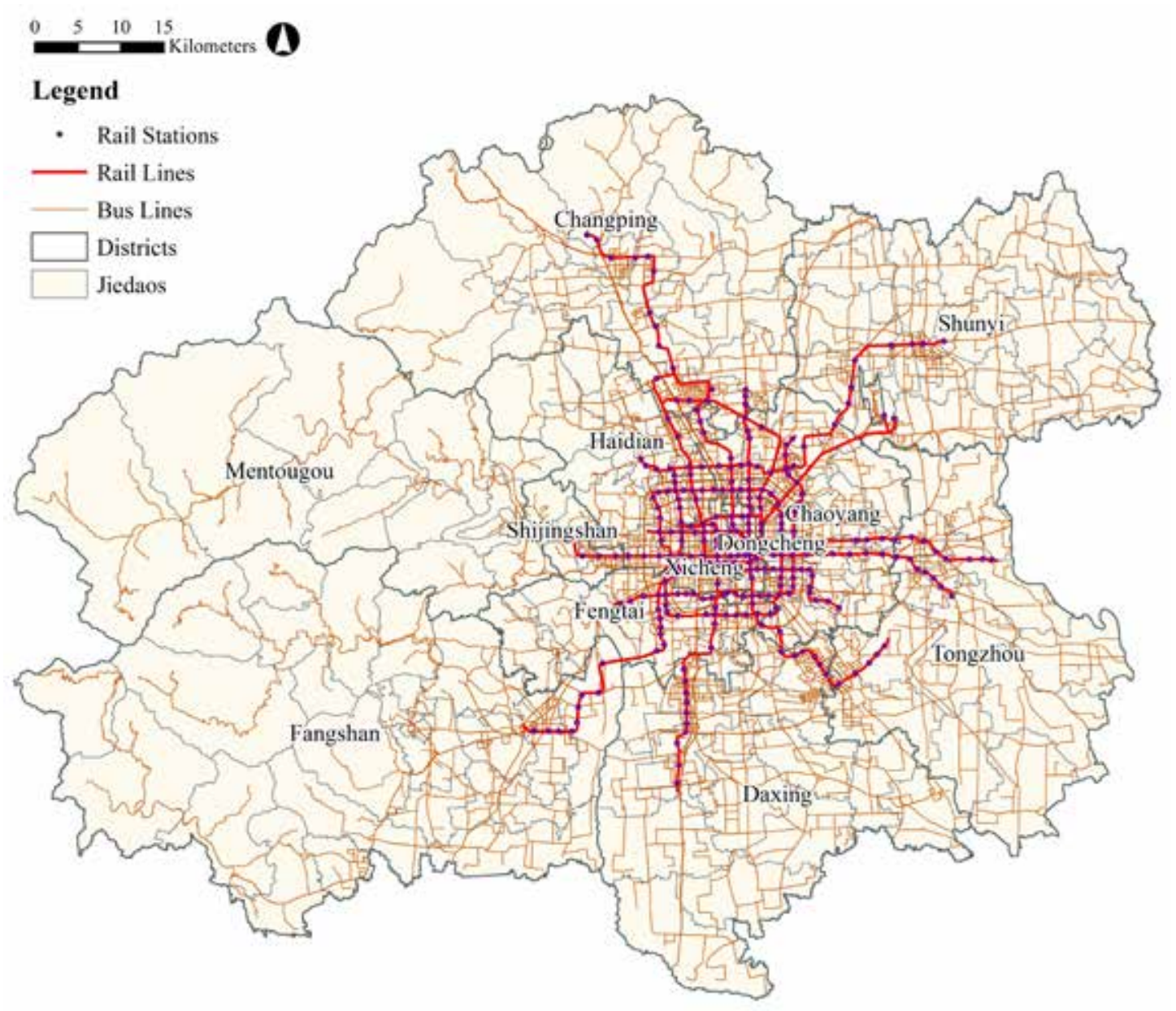

Figure 1: Map of study area

Data on total employment and employment by industry sectors come from the 2013 Economic Census, and data on total population and population with different educational attainment and hukou status come from the 2010 Population Census. In China, the migrant population without local hukou is socio-economically disadvantaged because China's social welfare provision is tied to the local jurisdictions where people officially registere their hukou. Migrants who live outside their officially registered jurisdictions are often denied state-provided education, housing, social security, and economic opportunities (Fan, 2002). Besides hukou, we use educational attainment rather than income to indicate socio-economic status. This is because China's Population Census does not provide income data but rather, educational attainment data at the jiedao level. We define the population without college degrees as the low-educated population, and vice versa. As shown in Table 1, migrants accounted for $37.9 \%$ of total population in the Beijing metropolitan area in 2010. Of the 6.54 million migrant population, the majority of them (4.92 million) had no college degree. Table 1 also shows that jobs were not evenly distributed across sectors in 2013. 
Table 1: Population and employment in Beijing Metropolitan Area

\begin{tabular}{|c|c|c|}
\hline Population Groups & Population (in million) & Share of total \\
\hline High-educated Local & 4.33 & $25.1 \%$ \\
\hline High-educated Migrant & 1.62 & $9.4 \%$ \\
\hline Low-educated Local & 6.41 & $37.1 \%$ \\
\hline Low-educated Migrant & 4.92 & $28.5 \%$ \\
\hline Total Population (aged $6 \&$ older) & $\mathbf{1 7 . 2 8}$ & \\
\hline Employment Sectors & Employment (in million) & Share of total \\
\hline Mining & 0.06 & $0.6 \%$ \\
\hline Manufacturing & 1.23 & $11.7 \%$ \\
\hline Utilities & 0.09 & $0.8 \%$ \\
\hline Construction & 0.60 & $5.7 \%$ \\
\hline Wholesale and Retail Trades & 1.43 & $13.5 \%$ \\
\hline Transport, Storage and Post & 0.66 & $6.3 \%$ \\
\hline Hotels and Catering Services & 0.49 & $4.6 \%$ \\
\hline Information, Computer Services and Software & 0.93 & $8.8 \%$ \\
\hline Finance & 0.43 & $4.1 \%$ \\
\hline Real Estate & 0.54 & $5.1 \%$ \\
\hline Leasing and Business Services & 1.37 & $12.9 \%$ \\
\hline Scientific Research and Technical Service & 0.94 & $8.9 \%$ \\
\hline Management of Public Facilities & 0.11 & $1.0 \%$ \\
\hline Services to Households and Other Services & 0.20 & $1.9 \%$ \\
\hline Education & 0.50 & $4.7 \%$ \\
\hline Health, Social Security and Welfare & 0.26 & $2.5 \%$ \\
\hline Culture, Sports and Entertainment & 0.27 & $2.5 \%$ \\
\hline Public Management and Social Organization & 0.45 & $4.2 \%$ \\
\hline Total Employment & 10.56 & \\
\hline
\end{tabular}

Transit network data in this research was obtained from the Baidu Direction API (see more details at http://developer.baidu.com/map/index.php?title=webapi/direction-api). Baidu is a web service company that offers mapping solutions in China, which allows the user to query travel directions and total travel time between any two points (as long as the longitudes and latitudes are given) using either the car or transit mode. The total transit travel time given by the Baidu Direction API automatically includes bus/rail riding time, walking time, and waiting time derived from the frequency/headway of a specific bus route at a specific time of day. To generate the morning peak-hour transit travel time, we queried the Baidu Direction API during 7-9 am local time in Beijing in 2015.

\section{$3 \quad$ Methodology}

\subsection{Measure of employment distribution}

An understanding of the employment distribution within the metro area is essential to analyze the job accessibility. We use the decentralization index proposed by Galster et al. (2001) to quantify the extent to which jobs are centralized or dispersed in the study area. The index is measured by the weighted average distance of employment from the Central Business District (CBD): 


$$
D I=\sum_{i=1}^{n} e_{i} D C B D_{i} / E
$$

where $e_{i}$ is the number of employment in jiedao $\mathrm{i}, \mathrm{E}$ is the total metropolitan employment, and $\mathrm{DCBD}_{\mathrm{i}}$ is the Euclid distance of jiedao $\mathrm{i}$ (centroid point) from the CBD.

\subsection{Measure of job accessibility via transit}

Researchers have developed multiple methods for measuring job accessibility. These methods range from the simplest form that calculates the linear distance to the nearest job center, to the cumulative opportunities approach that counts the total number of jobs within a travel distance or a given travel time, to more complicated measures that use the distance decay function and take job competition into consideration (Cheng \& Bertolini, 2013; Horner \& Downs, 2014). In this study, we apply a cumulative opportunity approach to calculate the transit-based job accessibility. This method is easy to interpret and has been used for comparing job accessibility across different population groups (Tilahun \& Fan, 2014).

The cumulative measure reflects the total number of jobs reachable within a predetermined travel time during morning peak hours. The 2015 Beijing travel survey indicates that the average travel time by bus and by rail in morning peak hours is 60.5 and 62.3 minutes, respectively (Beijing Transport Institute, 2016). Therefore, we use 60 minutes as the travel time threshold to calculate the accessibility measure. The calculation involves two steps. First, we generate the transit travel time matrix using the Baidu Direction API, which describes the shortest transit travel time between each pair of jiedaos (centroids). Then, the total number of jobs accessible within 60 minutes of transit travel are added up for each jiedao based on the transit travel time matrix. To standardize the accessibility measure, we convert the raw counts of jobs into the percentage of the total metropolitan employment. The formula is as followed:

$$
\begin{aligned}
& A_{i}=\sum_{j=1}^{n} e_{j} f\left(t_{i j}\right) / E \\
& f\left(t_{i j}\right)=\left\{\begin{array}{l}
1 ; \text { if } t_{i j} \leq 60 \text { minutes } \\
0 ; \text { if } t_{i j}>60 \text { minutes }
\end{array}\right.
\end{aligned}
$$

where, $A_{i}$ represents the share of metropolitan jobs accessible within 60 minutes of transit travel from jiedao $\mathrm{i}, \mathrm{e}_{\mathrm{j}}$ is the employment at jiedao $\mathrm{j}$, and $\mathrm{E}$ is the total metropolitan employment. $\mathrm{t}_{\mathrm{ij}}$ represents the travel time by transit between the centroid of jiedao i and the centroid of jiedao j. As illustrated, whether jobs are considered accessible is dependent on a travel time threshold function $\mathrm{f}\left(\mathrm{t}_{\mathrm{ij}}\right)$. Note that the accessibility measure above can be applied to calculate the general accessibility to all metropolitan employment as well as the accessibility to jobs in a specific sector. For a specific sector, $e_{j}$ is the employment in the sector at jiedao $j$, and $E$ is the total metropolitan employment in that specific sector.

Besides jiedao-level accessibility measures, we further calculate an aggregated metropolitan-level accessibility measure. This measure is calculated as the average share of jobs reachable within 60 minutes across all jiedaos weighted by jiedao population. The formula is as followed:

$$
A_{m}=\sum_{i=1}^{n} p_{i} A_{i} / P
$$

where, $A_{m}$ represents the metro-wide job accessibility, $A_{i}$ and $p_{i}$ are the job accessibility and population of jiedao $\mathrm{i}$, respectively, and $\mathrm{P}$ is the total population of the metropolitan area. Likewise, this measure can be applied to calculate metro-wide accessibility to jobs in a specific sector. In addition, the metro-wide accessibility metric can also be applied to generate population-specific measures. For example, $\mathrm{p}_{\mathrm{i}}$ can be 
regarded as not only the total population of jiedao i , but also the total low-educated population of jiedao i to calculate the metro-wide accessibility measure specifically for low-educated population.

\section{$4 \quad$ Results}

\subsection{Metro-wide job accessibility by sectors}

Across all jiedaos, the average metro-wide 60 -minute job accessibility by transit in the Beijing metropolitan area is $18.4 \%$, which means Beijing residents on average can reach $18.4 \%$ of all metropolitan jobs (i.e., 1.84 million jobs) within one hour of travel time by way of the existing transit system in the metropolitan area. When comparing among different sectors, there are wide disparities in average transit-based job accessibility. As shown in Figure 2, the most-accessible sector is finance, with $34.8 \%$ of metropolitan finance jobs reachable via transit within one hour of travel time, and the least-accessible sector is manufacturing, with only $5.2 \%$ of jobs in the sector reachable by transit within one hour. There are four sectors with an average accessibility less than that of total jobs, namely manufacturing, construction, transport, storage and post, and services to households and other services.

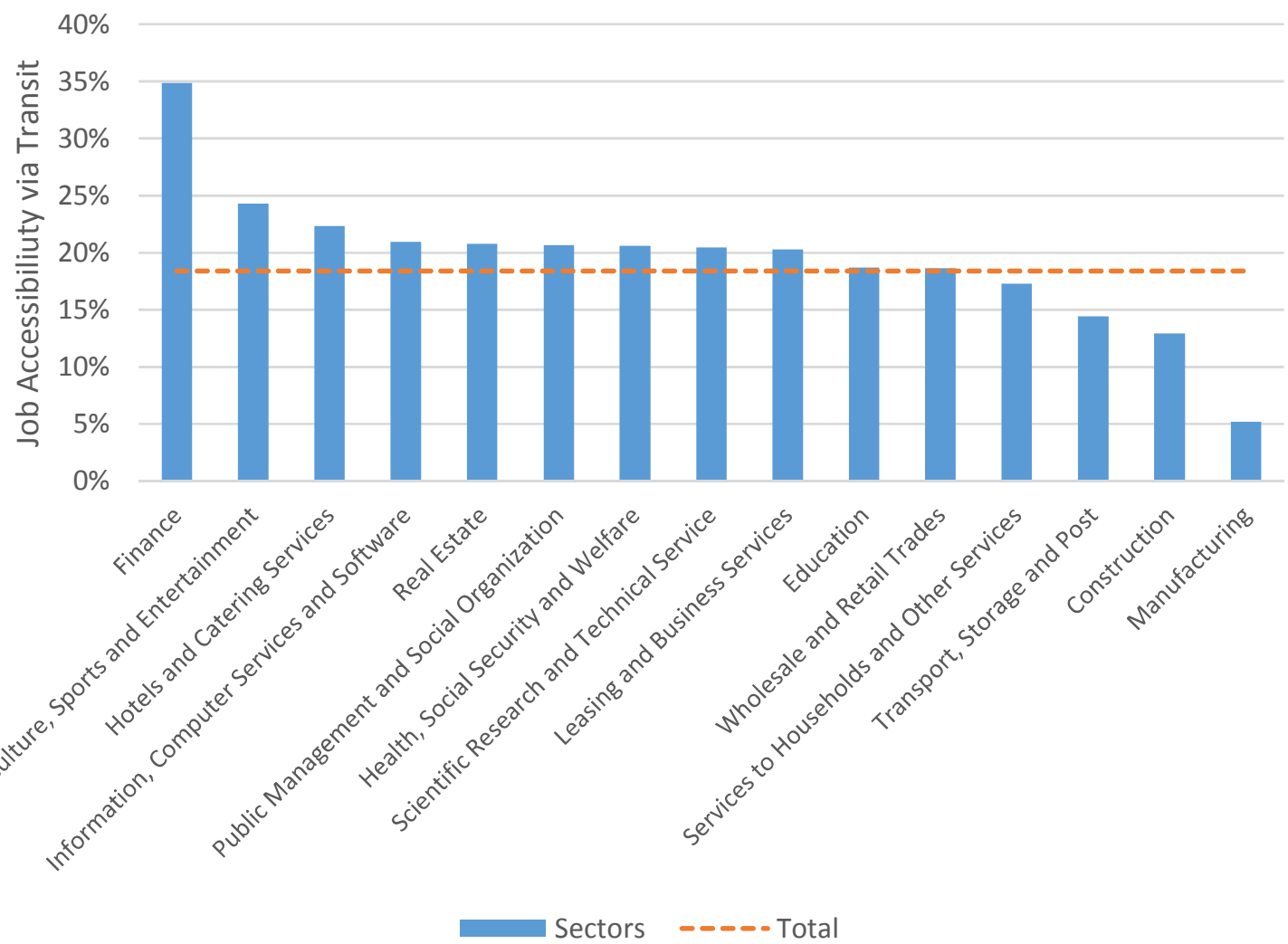

Figure 2: Job accessibility via transit by sectors

\subsection{Job accessibility, employment decentralization and educational requirement of jobs}

Figure 3 (top) shows that the job accessibility levels of sectors are highly correlated with the decentralization index. Jobs in sectors that have suburbanized extensively in the metropolitan area, such as manufacturing and construction, are the least accessible by transit. In contrast, sectors with a high concentration of jobs in the urban core have higher transit-based job accessibility. The strong correlation between the 
decentralization index and the job accessibility measure underscores the city-centric nature of the transit system in Beijing.

Figure 3 (bottom) shows a strong correlation between the transit-based job accessibility of a sector and the share of jobs requiring college education in the sector. Sectors with fewer jobs requiring college education are sectors with lower job accessibility by transit. This is a cause for concern because sectors with fewer jobs requiring college education tend to be sectors that are more suitable for job placement among low-educated populations who are more transit dependent.
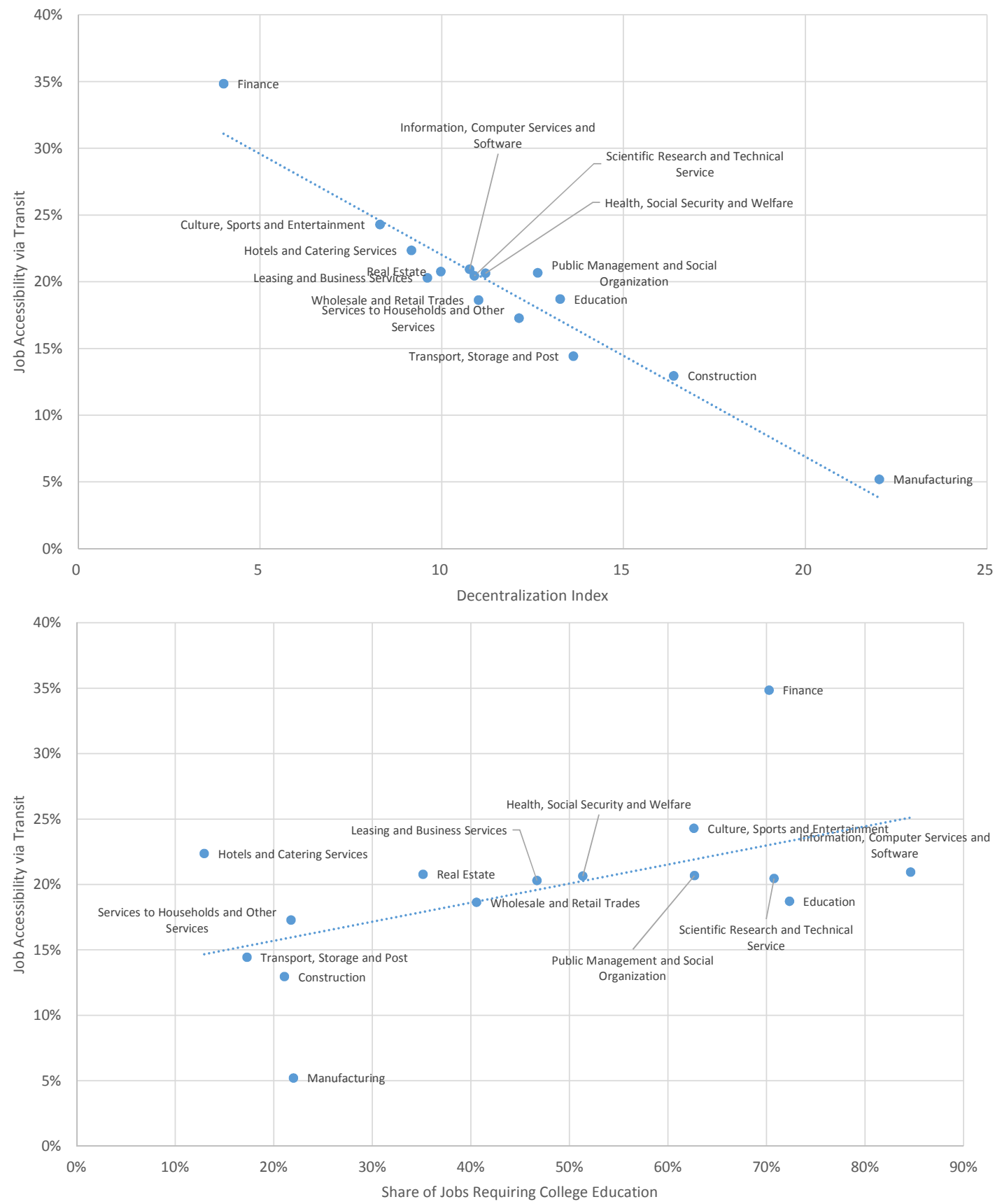

Figure 3: Job accessibility plotted against employment decentralization and share of jobs requiring college education by sectors 


\subsection{Spatial distribution of jiedao-level job accessibility}

The sectoral disparities in job accessibility is also evident in Figure 4, which shows jiedao-level accessibility for all jobs, jobs in the finance sector, and jobs in the manufacturing sector. The finance and manufacturing sectors offer a strong contrast because, at the metropolitan level, finance jobs are the most accessible by transit and manufacturing jobs are the least accessible (as shown in Figure 2). The extensively suburbanized manufacturing jobs are not very reachable by transit across the metropolitan area due to the limited availability of transit services in the suburban areas connecting the suburbanized jobs.
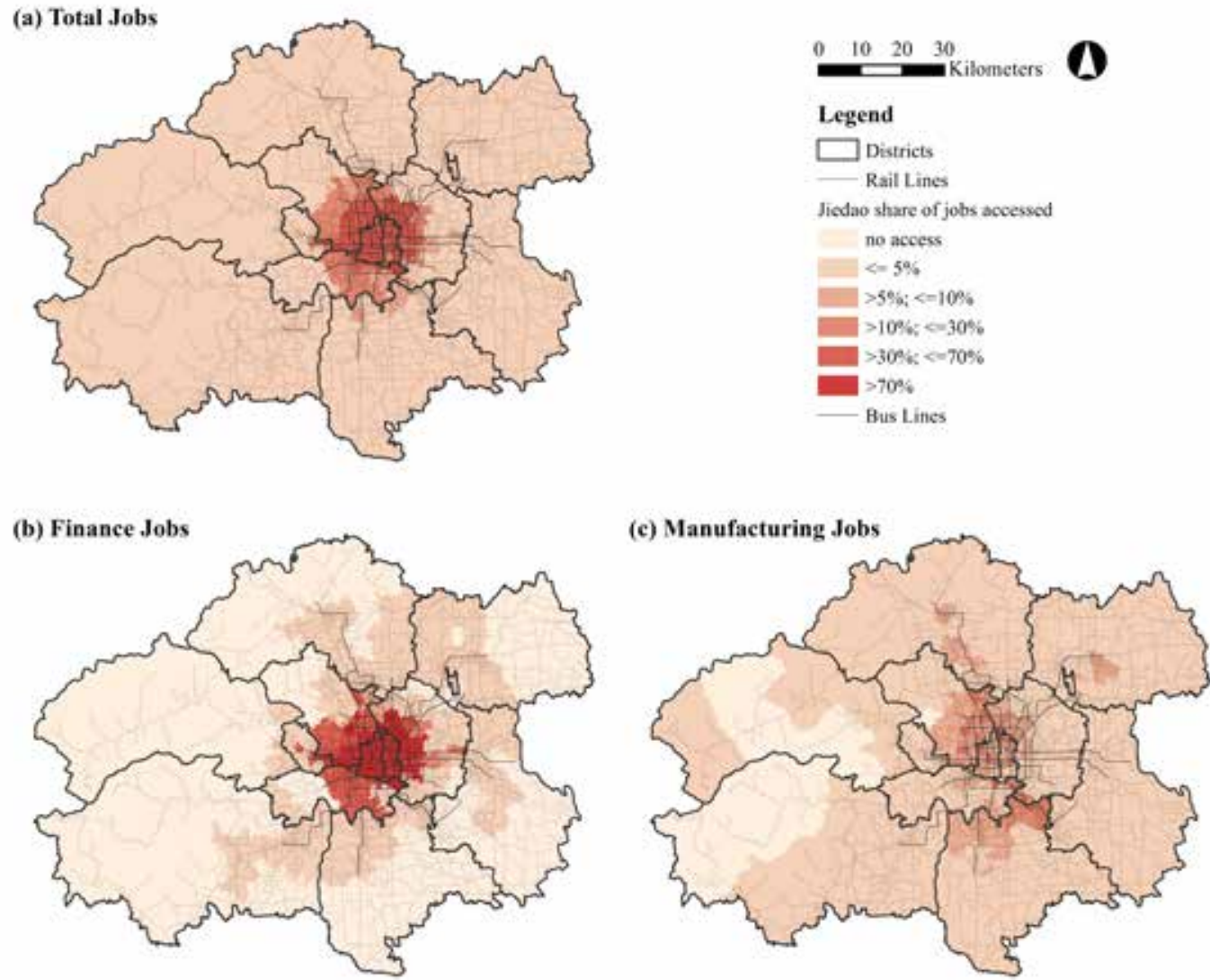

Figure 4: Jiedao share of total jobs and jobs in finance and manufacturing reachable via transit in 60 minutes

To vividly describe the sectoral differences in transit-based job accessibility among all sectors, Figure 5 plots the difference between the total and sector job accessibility at each jiedao against the jiedao's distance from the CBD for all sectors. The loess curves are fitted to better identify patterns of the differences (the smoothing parameter is 0.3 ). We only show the patterns at locations within 25 kilometers of the CBD because, at locations more than 25 kilometers outside of the CBD, the differences between the total and sector job accessibility become minimal.

In Figure 5, sectors are grouped according to their metro-wide job accessibility from high to low levels. The patterns of differences between the total and sector job accessibility vary considerably by sector. As compared to total jobs, finance jobs are much more accessible within 5 kilometers of the CBD. Several other sectors, such as culture, sports, and entertainment; hotel and catering services; leasing and business services; and real estate, show the similar distribution patterns but not as significantly as 
finance. In contrast, jobs in manufacturing, construction, and transport, storage and post sectors are much less accessible than total jobs within 10 kilometers of the CBD. This is not surprising because these jobs are the most spatially dispersed in the metropolitan area.

Among all sectors, three sectors (information, computer services and software; scientific research and technical service; and education) are the most unique. Their loess curves show the humps in places that are 10-15 kilometers away from the CBD, indicating that access to jobs in these three sectors is highest at locations 10-15 kilometers away from the CBD (rather than at central locations). Although unique, the results are reasonable because location choices in these three sectors in Chinese cities are often dictated by governments' creation of science and technology parks and higher education districts (also refereed as university parks) at urban fringe locations.
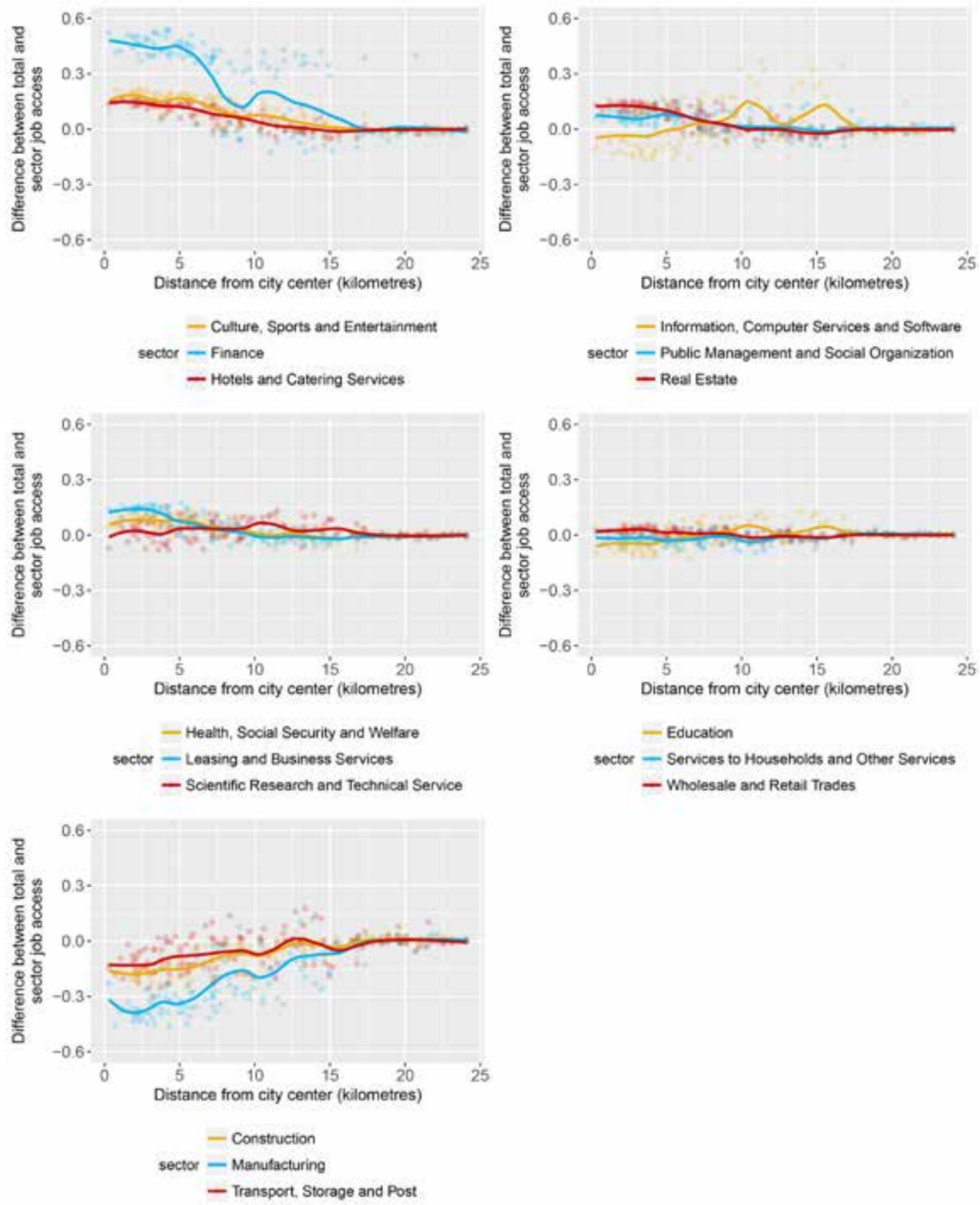

Figure 5: Difference between the total and the sector job accessibility at the jiedao against the distance from the CBD with the loess fit by sectors 


\section{4}

Job accessibility by sectors for different population groups

Figure 6 summarizes metro-wide accessibility levels across sectors and across population groups. Among the four population groups, the most advantaged group — high-educated local residents — has the highest job accessibility levels across all sectors, while the most disadvantaged — low-educated migrants - has the lowest levels across all sectors. On average, a typical local resident with a college degree can reach $48.3 \%$ of all finance jobs by transit within one hour, while a typical migrant without a college degree can only reach $27.2 \%$ of all finance jobs in the metropolitan area. The analysis also shows that the disparities in job accessibility are especially large when tying specific populations with specific sectors. Within 60 minutes, low-educated migrants using transit on average can only access $4.6 \%$ of the total manufacturing jobs. In contrast, the same measure for the high-educated local population accessing jobs in finance is as high as $48.3 \%$.

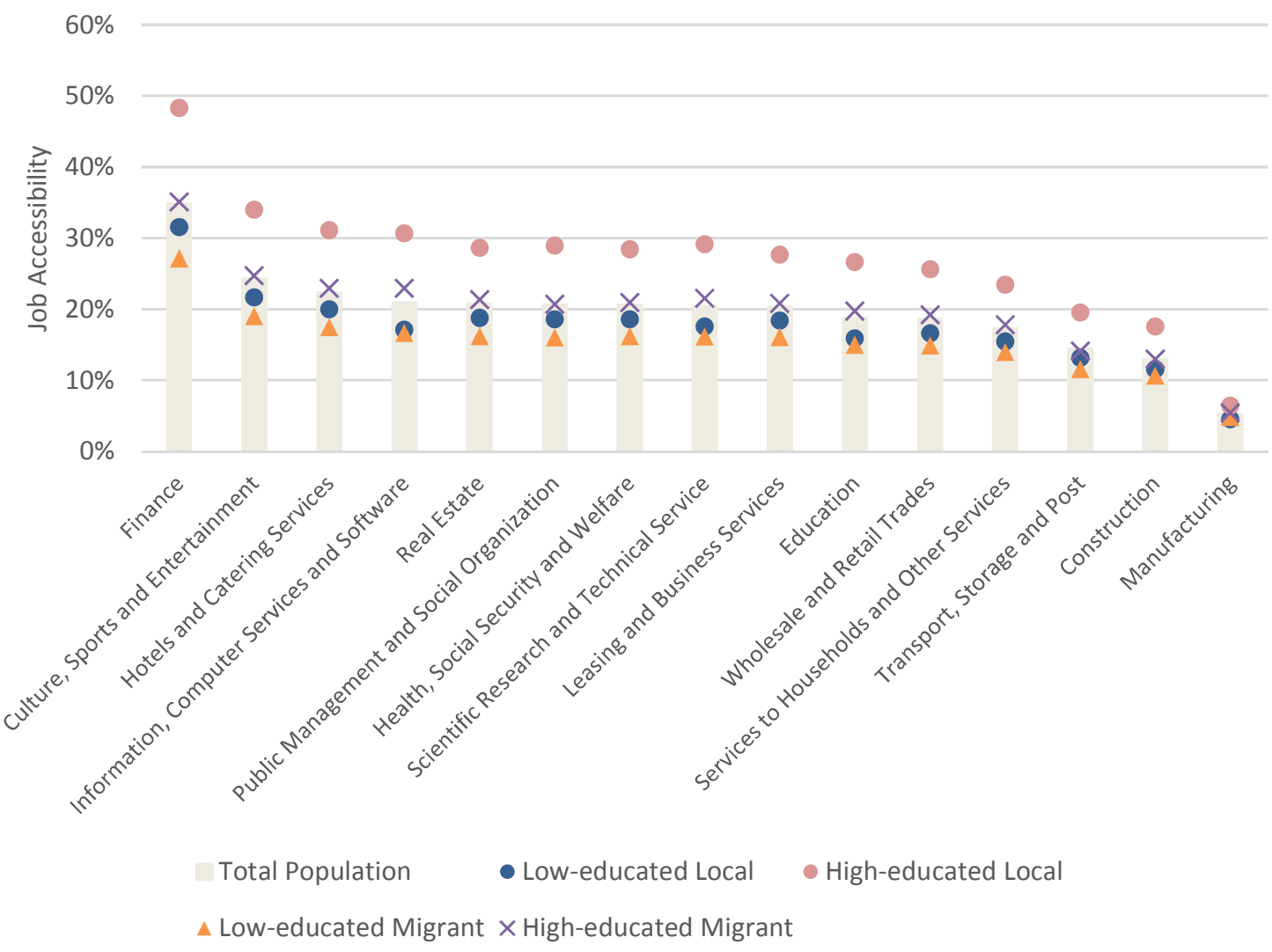

Figure 6: Job accessibility via transit for four population groups by sectors

\section{Conclusion}

By examining sectoral and population disparities in job accessibility via transit in the Beijing metropolitan area, our study provides the first-hand and comprehensive evidence on unequal job access between migrant and local populations and between high- and low-educated populations. The findings suggest that general transit improvements and jobs/population redistribution efforts without specific sectoral and population considerations are unlikely to create equal access to job opportunities. 
The strong, negative correlation between sector job accessibility and the decentralization index suggests that the existing transit system in Beijing serves centralized jobs much better than decentralized jobs. Dependent upon the characteristics of jobs in a specific sector, employers and local governments may carry out coordinate efforts to improve job accessibility. In sectors where job centralization is practically impossible, employers and local governments may provide customized transit services to meet the job access demand. In sectors where job centralization is possible, employers and local governments may strategically create jobs at urban infill locations.

The strong, positive correlation between sector job accessibility and the share of jobs requiring college education raises critical equity concerns for disadvantaged population groups who are more transit dependent and in need of employment opportunities with lower educational requirements. The results show that disadvantaged population groups in Beijing are facing a paradox: they are more transitdependent and yet their suitable jobs are not well served by transit. This paradox situation is further exacerbated by the population distribution patterns. After taking into account the population distribution patterns, the job accessibility levels of low-educated migrant population are always the lowest among the four population groups, regardless of the employment sector. So low-educated migrants are the most disadvantaged group in terms of job accessibility by transit. Most concerning is that we observed the lowest accessibility when examining the accessibility level of low-educated migrants to sector jobs with low educational requirements.

The results suggest that greater attention must be paid to better connect low-educated migrant population to job opportunities, especially connecting them to jobs in manufacturing, construction, and transportation and storage sectors that are often decentralized (i.e., not well-served by existing transit) and have lower educational requirements (i.e., more job placement opportunities for low-educated migrants).

In Chinese cities, efforts must be made to coordinate multiple policies to mitigate the apparent spatial mismatch that disadvantaged population groups are facing and improve the access equity among residents, such as locating affordable housing near the transit infrastructure, particularly in suburban areas, and initiating job creation programs in urban fringe areas where low-educated migrant populations are concentrated. The government efforts to establish the science and technology parks and higher education districts at urban fringe locations are not helpful to mitigate the spatial mismatch problem since decentralized low-educated residents and migrants are usually not qualified for those jobs.

\section{Acknowledgements}

Supported by the National Natural Science Foundation of China (Grant No. 41371005). 


\section{References}

Beijing Municipal Bureau of Statistics. (2016). Beijing statistical yearbook 2016. Beijing: China Statistics Press.

Beijing Transport Institute. (2016). Beijing transport annual report 2016. Retrieved from http://www. bjtrc.org.cn/JGJS.aspx?id=5.2\&Menu=GZCG

Cheng, J., \& Bertolini, L. (2013). Measuring urban job accessibility with distance decay, competition and diversity. Journal of Transport Geography, 30, 100-109. doi: 10.1016/j.jtrangeo.2013.03.005

Delbosc, A., \& Currie, G. (2011). Using Lorenz curves to assess public transport equity. Journal of Transport Geography, 19(6), 1252-1259. doi:10.1016/j.jtrangeo.2011.02.008

Engels, B., \& Liu, G. J. (2011). Social exclusion, location and transport disadvantage amongst nondriving seniors in a Melbourne municipality, Australia. Journal of Transport Geography, 19(4), 984 996. doi:10.1016/j.jtrangeo.2011.03.007

Fan, C. C. (2002). The elite, the natives, and the outsiders: Migration and labor market segmentation in urban China. Annals of the Association of American Geographers, 92(1), 103-124. doi: 10.1111/14678306.00282

Fan, Y. (2012). The planners' war against spatial mismatch: Lessons learned and ways forward. Journal of Planning Literature, 27(2), 153-169. doi: 10.1177/0885412211431984

Fan, Y., Allen, R., \& Sun, T. (2014). Spatial mismatch in Beijing, China: Implications of job accessibility for Chinese low-wage workers. Habitat International, 44, 202-210. doi: 10.1016/j.habitatint.2014.06.002

Fan, Y., Guthrie, A., \& Levinson, D. (2012). Impact of light-rail implementation on labor market accessibility: A transportation equity perspective. Journal of Transport and Land Use, 5(3), 28-39. doi: 10.5198/jtlu.v5i3.240

Galster, G., Hanson, R., Ratcliffe, M. R., Wolman, H., Coleman, S., \& Freihage, J. (2001). Wrestling sprawl to the ground: Defining and measuring an elusive concept. Housing Policy Debate, 12, 681-717. doi: 10.1080/10511482.2001.9521426

Gu, C., Wang, F. \& Liu, G. (2005). The structure of social space in Beijing in 1998: A socialist city in transition. Urban Geography, 26(2), 167-192. doi: 10.2747/0272-3638.26.2.167

Horner, M. W., \& Downs, J. A. (2014). Integrating people and place: A density-based measure for assessing accessibility to opportunities. Journal of Transport and Land Use, 7(2), 23-40. doi: 10.5198/ jtlu.v7i2.417

Hu, L. (2017). Job accessibility and employment outcomes: Which income groups benefit the most? Transportation, 44(6), 1421-1443. doi: 10.1007/s11116-016-9708-4

Jiang, H., \& Levinson, D. (2017). Accessibility and the evaluation of investments on the Beijing subway. Journal of Transport and Land Use, 10(1), 395-408. doi: 10.5198/jtlu.2016.884

Leck, E., Bekhor, S., \& Gat, D. (2008). Equity impacts of transportation improvements on core and peripheral cities. Journal of Transport and Land Use, 1(2), 153-182.

Lubin, A., \& Deka, D. (2012). Role of public transportation as job access mode: Lessons from survey of people with disabilities in New Jersey. Transportation Research Record: Journal of the Transportation Research Board, 2277, 90-97. doi: 10.3141/2277-11

Matas, A., Raymond, J. L., \& Roig, J. L. (2010). Job accessibility and female employment probability: The cases of Barcelona and Madrid. Urban Studies, 47(4), 769-787. doi: 10.1177/0042098009352364

Niedzielski, M. A., \& Eric Boschmann, E. (2014). Travel time and distance as relative accessibility in the journey to work. Annals of the Association of American Geographers, 104(6), 1156-1182. doi: $10.1080 / 00045608.2014 .958398$ 
Qi, Y., Fan, Y., Sun, T., \& Hu, L. (2018). Decade-long changes in spatial mismatch in Beijing, China: Are disadvantaged populations better or worse off? Environment and Planning A: Economy and Space, 50(4), 848-868. doi: 10.1177/0308518X18755747

Sanchez, T. W. (1999). The connection between public transit and employment: The cases of Portland and Atlanta. Journal of the American Planning Association, 65(3), 284-296. doi: $10.1080 / 01944369908976058$

Sun, T., Han, Z., Wang, L., \& Li, G. (2012). Suburbanization and subcentering of population in Beijing metropolitan area: A nonparametric analysis. Chinese Geographical Science, 22(4), 472-482. doi: 10.1007/s11769-012-0547-8

Tilahun, N., \& Fan, Y. (2014). Transit and job accessibility: An empirical study of access to competitive clusters and regional growth strategies for enhancing transit accessibility. Transport Policy, 33, 17-25. doi: 10.1016/j.tranpol.2014.02.002

Welch, T. F. (2013). Equity in transport: The distribution of transit access and connectivity among affordable housing units. Transport Policy, 30, 283-293. doi: 10.1016/j.tranpol.2013.09.020

Xia, J. C., Nesbitt, J., Daley, R., Najnin, A., Litman, T., \& Tiwari, S. P. (2016). A multi-dimensional view of transport-related social exclusion: A comparative study of Greater Perth and Sydney. Transportation Research A: Policy and Practice, 94, 205-221. doi: 10.1016/j.tra.2016.09.009 